\title{
Pengurangan Penggunaan Plastik Pada UMKM Perkampungan Wisata Budaya Betawi Setu Babakan Jakarta
}

\author{
Haswan Yunaz ${ }^{1}$, Ahmad Nurdin Hasibuan², Dodi Wahab ${ }^{3}$, Reny Andriyanty*4 \\ 1,2,3,4Program Studi Manajemen Institut Bisnis dan Informatika (IBI) Kosgoro 1957 \\ *e-mail: haswanyunaz@yahoo.com ${ }^{1}$,nurdin_hsb@yahoo.com ${ }^{2}$,dodiwahab6@gmail.com ${ }^{3}$, \\ r.andriyanty@gmail.com ${ }^{*}$
}

\begin{abstract}
This program objection for assisting the government's efforts to reduce the plastics using in Indonesia, especially in South Jakarta. The expected benefit of the activity is the increasing of enviromental care insight by suppressing the plastic wrap using for small business unit in the Betawi Cultural Tourism Setu Babakan Village South Jakarta. The activity was counseling and discussion. The target audience was small and micro business units. The programme results are 92 percent of participants will suppress the use of plastic as a wrapper and 8 percent still do not have the desire to suppress the use of plastic wrap. 92 percent of them will try to apply the green marketing concept and there are still 8 percent who do not want to apply this concept. Ninety seven percent of participants stated that this activity provided benefits and increased understanding of reducing plastics using and the concept of green marketing.
\end{abstract}

Keywords: Plastics wrap, small business, Betawi culture

\begin{abstract}
Abstrak
Program ini dikembangkan dan dilaksanakan dengan tujuan untuk membantu upaya pemerintah dalam menekan penggunaan plastik di Indonesia khususnya di Jakarta Selatan. Manfaat kegiatan yang diharapkan adalah meningkatnya wawasan peduli lingkungan dengan menekan penggnaan plastik bagi pelaku UKM di Perkampungan Wisata Budaya Betawi Setu Babakan Jakarta. Sifat kegiatan adalah penyuluhan dengan metode tanya jawab antara khalayak sasaran dengan tim pelaksana. Khalayak sasaran kegiatan pengabdian ini adalah pelaku UMKM di Perkampungan Wisata Budaya Betawi Setu Babakan Jakarta. 92 persen peserta akan menekan penggunaan plastik sebagai pembungkus dan 8 persen nya masih belum memiliki keinginan untuk menekan penggunaan plastik pembungkus. 92 persen dari mereka akan berusaha untuk menerapkan konsep green marketing dan masih ada 8 persen yang tidak mau menerapkan konsep ini. 97 persen peserta yang menyatakan bahwa kegiatan pengabdian ini memberikan manfaat dan meningkatkan pemahaman mengenai pengurangan penggunaan plastik dan konsep green marketing.
\end{abstract}

Kata kunci: Pembungkus plastik, usaha kecil, wisata betawi

\section{PENDAHULUAN}

Plastik pada awalnya adalah bahan yang sangat murah sehingga bisa dijangkau oleh banyak industri. Diantaranya industri makanan dan minuman. Penggunaan plastik berkembang pesat sebagai pembungkus. Dan kemasan plastik mendominasi indutsri kemasan luwes pada angka 80 persen. Plastik adalah polimer sintesis. Menurut www.greenpeace .org didunia, produksi plastik di dunia dari tahun 1950 sampai tahun 2010 mengalami peningkatan yang signifikan. Hal tersebut dapat dilihat pada gambar berikut:

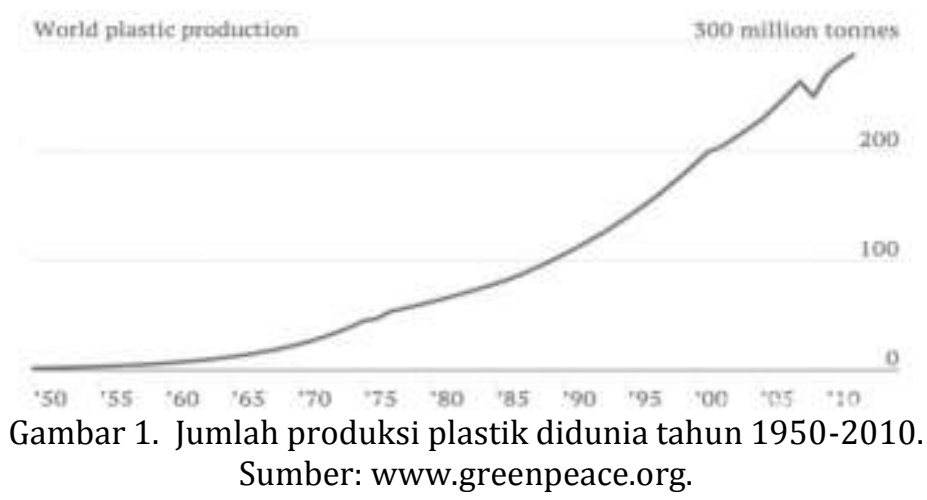


Penelitian Sahwan et al tahun 2005, menyebutkan pengunaan plastik sudah menyebar keseluruh aspek kehidupan masyarakat secara luas karena sifatnya yang tidak mudah rusak. Bahan plastik yang tidak dipakai maka akan dibuang. Data di DKI Jakarta dengan jumlah sampah 5.000 ton sampah maka jumlah sampah plastik akan mencapai 400 ton per hari (Badan Pusat Statistik, 2018). Terdapat beberapa kategori plastik yang dapat di daur-ulang dan memiliki nilai ekonomi seperti high density poly Ethylene. Produk tersebut berupa ember, jerigen dan botol plastik, umumnya akan dapat dicari pemulung untuk diperjualbelikan kembali. Sedangkan jenis kantung plastik, dan pembungkus yang terkategori poly propylene tidak dapat didaur ulang dan tidak memiliki nilai ekonomis sehingga akan meningkatkan jumlah sampah plastik (Sahwan et al., 2005). Plastik sebagai polimer sintesis merupakan bahan yang sulit didegradasi di alam (Dewi \& Yesti, 2018; Nisah, 2018; Haryono, Astrini, \& SR, 2001). Sehingga menyebabkan pencemaran lingkungan (Yana \& Badaruddin, 2017; Purwaningrum, 2016). Hal ini menunjukkan bahwa kebutuhan akan pengendalian sampah sangat dibutuhkan (Septiani, Arianie, Risman, Handayani, \& Kawuryan, 2019; Permata Dewi \& Yesti, 2018; Yana \& Badaruddin, 2017). Pengendalian sampah menjadi upaya terpadu dengan meningkatkan pemahaman masyarakat (Fitriah, Yusup, Fujiarti, Sudarmika, \& Ramadhanty, 2019; Sidjabat, Ismail, \& Rismauli, 2019).

Data BPS tahun 2018 terkait statistik lingkungan hidup Indonesia, dinyatakan bahwa jumlah sampah di Indonesia mencapai 65,2 juta ton per tahun dengan jumlah penduduk 261.115.456 orang dengan tren yang terus menigkat (BPS RI, 2019). Pertumbuhan jumlah penduduk yang makin meningkat akan makin meningkatkan jumlah sampah yang diproduksi. Hal ini harus diantisipasi lebih lanjut. Sampah menjadi masalah yang utama di Indonesia setidaknya disebabkan oleh enam hal. Hal tersebut adalah rendahnya kapasitas pemerintah daerah dalam pengelolaan sampah, ketidakpedulian masyarakat, tren sampah yang makin meningkat, rendahnya tanggung jawab industri, isu regulasi dan izin impor sampah (Bank Indonesia, 2013)

Terkait hal tersebut diatas, berdasarkan Perpres Nomer 97 Tahun 2018 mengenai kebijakan da strategi nasional pengelolaan sampah rumah tangga dan sampah sejenis sampah rumah tangga (SRT \& SSRT) disebutkan bahwa upaya yang harus dilakukan dalam pengurangan jumlah sampah sebanyak 30 persen dan upaya penanganan jumlah sampah sebanyak 70 persen (Peraturan Pemerinta Indonesia, 2017). Perkampungan Budaya Setu Babakan dengan potensi pengunjung sebanyak 10.000 orang merupakan daerah cagar budaya sesuai Peraturan Daerah Provinsi DKI Jakarta Nomor 3 Tahun 2005 (DKI Jakarta, 2005). Sebagai cagar budaya, maka dipandang perlu tindakan-tindakan pelestarian lingkungan dan terkait dukungan upaya pemerintah untuk mengurangi jumlah sampah, maka tim memandang perlu dilakukannya "manajemen penggunaan plastik sebagai strategi green marketing pada usaha kecil menengah (UMKM) di Perkampungan Wisata Budaya Betawi Setu Babakan Jakarta. Program ini dikembangkan dan dilaksanakan dengan tujuan untuk membantu upaya pemerintah dalam menekan penggunaan plastik di Indonesia khususnya di Jakarta Selatan. Dalam pengelolaan kawasan cagar budaya diperlukan upaya menyeluruh sehingga menjadi kawasan wisata unggul (Hayati \& Suryasih, 2019). Manfaat kegiatan yang diharapkan adalah meningkatnya wawasan peduli lingkungan dengan menekan pengunaan plastik bagi pelaku UKM di Perkampungan Wisata Budaya Betawi Setu Babakan Jakarta.

\section{METODE}

Sifat kegiatan adalah penyuluhan dengan metode tanya jawab antara khalayak sasaran dengan tim pelaksana. Terkait peningkatan kualitas lingkungan budaya Betawi, dimana banyak pelaku UMKM induri makanan dan minuman yang masih masif menggunakan plastik sebagai pembungkus. Fakta bahwa pencemaran lingkungan yang diakibatkan oleh industri disebabkan karena rendahnya kesadaran, lebih tepatnya pengetahuan pelaku usaha dalam menjaga lingkungan hidup sekitarnya. Maka diperlukan suatu upaya penyuluhan penggunaan plastik dan penerapan konsep green marketing. Data dari Bank Indonesia, 54 persen industri di Indonesia dari berbagai skala usaha masih belum mengetahui mengenai aktivitas ramah lingkungan yang terkait bisnisnya (Bank Indonesia, 2012). Dalam menjaga kualitas lingkungan hal mendasar yang perlu dilakukan adalah peningkatan kesadaran UMKM terhadap kelestarian lingkungan. Sehingga 
khalayak sasaran kegiatan pengabdian ini adalah pelaku UMKM di Perkampungan Wisata Budaya Betawi Setu Babakan Jakarta.

Pelaksanaan kegiatan terdiri atas dua kegiatan pokok, yaitu :

1. Kegiatan penyuluhan pertama. Kegiatan ini merupakan sharing ilmu dan diskusi mengenai dampak sampah plastik terhadap lingkungan manusia dan khususnya pada kelestarian lingkungan di Cagar Budaya Betawi Setu Babakan Jagakarsa Jakarta Selatan. Kegiatan ini dihadiri oleh 44 peserta pelaku UKM muda di Setu Babakan. Berikut adalah foto peserta kegiatan penyuluhan:

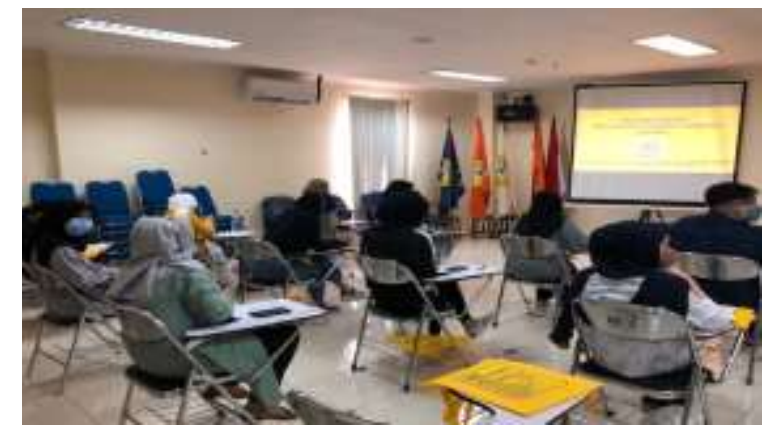

Gambar 2. Peserta kegiatan penyuluhan. Sumber: Dokumen LPPM IBI Kosgoro 1957

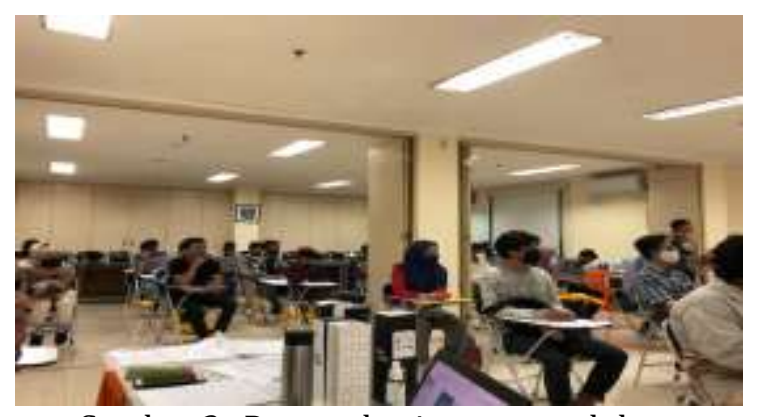

Gambar 3. Peserta kegiatan penyuluhan. Sumber: Dokumen LPPM IBI Kosgoro 1957

2. Kegiatan penyuluhan kedua. Kegiatan ini merupakan penyuluhan mengenai pengaplikasian konsep green marketing dengan tindakan pelaku UKM yang mengurangi pengunaan plastik pembungkus. Kegiatan ini diharapkan dapat membantu para pelaku UKM untuk dapat memposisikan produk, harga, tempat dan promosi secara efektif dan efisien. Kegiatan ini dihadiri oleh 38 peserta pelaku UKM muda di Setu Babakan. Berikut beberapa foto kegiatan yang telah dilaksanakan :

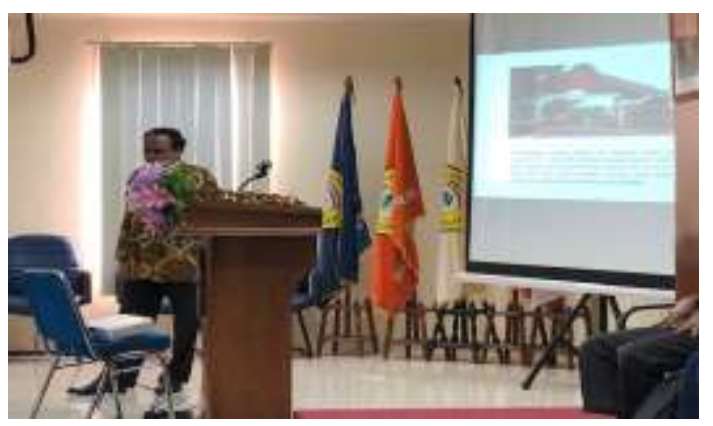

Gambar 4. Dosen pelaksana sedang memberikan penyuluhan. Sumber: Dokumen LPPM IBI Kosgoro 1957 


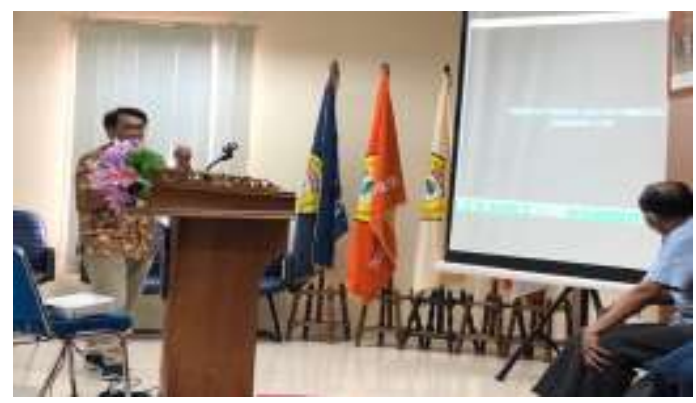

Gambar 5. Dosen pelaksana sedang memberikan penyuluhan. Sumber: Dokumen LPPM IBI Kosgoro 1957

3. Kegiatan evaluasi kegiatan. Pada kegiatan ini para peserta yang hadir mengisi kuisioner pra dan pasca penyuluhan. Tujuan kegiatan ini adalah untuk menilai dampak kegiatan terhadap pemahaman peserta.

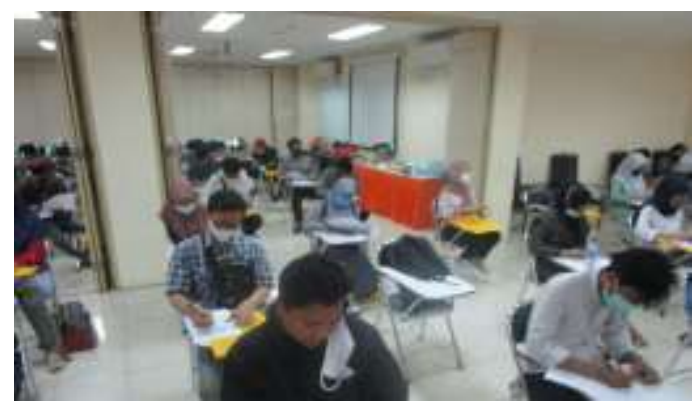

Gambar 6. Peserta penyuluhan sedang mengisi kuisioner pasca kegiatan. Sumber: Dokumen LPPM IBI Kosgoro 1957

Cara mengukur tingkat ketercapaian keberhasilan kegiatan pengabdian dilakukan berdasarkan penilaian tingkat pemahaman peserta, pra dan pasca kegiatan pengabdian. Tingkat ketercapaian dapat dilihat dari sisi perubahan sikap atas penggunaan plastik dalam usaha peserta kegiatan pengabdian.

\section{HASIL DAN PEMBAHASAN}

Pelaksanaan kegiatan pengabdian kepada masyarakat ini terdapat beberapa hal yang menjadi bahan materi penyuluhan. Diantaranya konsep bahan dasar plastik, bahaya penggunaan plastik, bagaimana menekan penggunaan plastik serta pengkolaborasian konsep green marketing bagi para pelaku UKM di Setu Babakan.

Plastik adalah senyawa organik yang sangat mudah dibentuk, memiliki rantai yang sangat panjang karena dibentuk dari polimerisasi bahan organik dan punya berat molekul yang sangat besar. Terbuat dari karbon, hidrogen dan atom - atom lainnya yang terikat dalam rantai molekul panjang yang disebut polimer (Pelley, 2018). Saat ini, plastik banyak digunakan sebagai pembungkus makanan dan minuman sekali pakai. Karena penggunaannya sekali pakai, maka menimbulkan sampah. Data di DKI Jakarta dengan jumlah sampah 5.000 ton sampah maka jumlah sampah plastik akan mencapai 400 ton per hari. Plastik sebagai polimer dan memiliki rantai karbon yang sangat panjang menjadi sulit diurai oleh mikroorganisme didalam tanah (Hahladakis, Velis, Weber, Iacovidou, \& Purnell, 2018). Penguraian plastik dialam memerlukan ratusan/ribuan tahun agar dapat hancur sempurna.

Kebanyakan plastik agar tidak kaku dan rapuh, diberi zat pelembut: (epoxidized soybean oil (ESBO), di(2-ethylhexyl)adipate (DEHA), bifenil poliklorin (PCB), acetyl tributyl citrate (ATBC) dan di(2-ethylhexyl) phthalate (DEHP) (Hahladakis et al., 2018). Zat tersebut dapat terserap ke makanan yang dimakan manusia dan dapat menyebabkan : 
- pigmentasi pada kulit dan benjolan-benjolan,

- gangguan pada perut,

- tangan dan kaki lemas.

- Sedangkan pada wanita hamil, mengakibatkan kematian bayi dalam kandungan serta bayi lahir cacat.

- Kasus terburuk adalah kanker hati/kulit (Karuniastuti, 2016).

Perpres Nomer 97 Tahun 2018 mengenai kebijakan dan strategi nasional pengelolaan sampah rumah tangga dan sampah sejenis sampah rumah tangga (SRT \& SSRT) disebutkan bahwa masyarakat harus mengurangi jumlah sampah sebanyak 30 persen dan meningkatkan upaya penanganan jumlah sampah sebanyak 70 persen.

Perkampungan Budaya Betawi Setu Babakan melalui SK Gubernur No. 9 Tahun 2000 ditetapkan sebagai kawasan Cagar Budaya Betawi dan menjadi destinasi wisata budaya betawi asli seluas 289 hektar yang memberikan berbagai atraksi wisata budaya dan wisata alam pemandangan setu Babakan. Potensi pengunjung mencapai 10.000 wisatawan. Selama ini Jakarta Selatan dikenal sebagai wilayah dengan lingkungan alam yang menyenangkan sehingga kita semua harus menjaga kelestarian lingkungan. Sehingga bagi pelaku UKM dalam memasarkan produknya harus :

1. Produk yang berbasis pada sumberdaya lokal

2. Menetapkan harga jual yang bersaing

3. Melakukan pemasaran diwilayah-wilayah yang menjaga kelestarian lingkungan

4. Melakukan promosi dimana produk bapak/ibu jual adalah produk yang peduli kepada lingkungan.

UKM di Setu Babakan pada dasarnya sudah menjalankan konsep green marketing. Hal yang perlu diperkuat dengan menekan penggunan plastik pembungkus dalam menjual produknya. Hal yang dapat dilakukan adalah :

1. mempergunakan piring lidi anyaman (karena ringan, aman dan tidak perlu dicuci)

2. Kembali memanfaatkan daun pisang/besek sebagai pembungkus

3. Mempergunakan sedotan berbahan bambu/daun kelapa/batang rumput

4. Dan kalaupun harus menggunakan plastik, pergunakan plastik berbahan dasar singkong yang dapat hancur produksi LIPI yang sudah banyak dipakai saat ini.

Alternatif pola pengelolaan sampah yang dapat dilakukan pelaku UKM di Setu Babakan adalah dengan melakukan kegiatan:

1. Reduce (Mengurangi): yaitu mengurangi produksi limbah sampah dengan cara memaksimalkan penggunaan barang dan menghindari dalam pemakaian barang sekali pakai. Misalnya, menggunakan sebuah kertas secara bolak-balik, membeli produk kemasan isi ulang atau dalam sebuah kemasan besar sekaligus.

2. Reuse (Memakai kembali): saat dalam membeli barang, pilihlah yang kemasannya bisa dipakai kembali, meskipun berbeda dengan fungsi yang awalnya. Contohnya, menggunakan kembali sebuah botol plastik menjadi wadah, bekas sebuah kaleng sebagai pot tanaman, dan sebagainya. Dengan begitu juga, waktu pemakaian barang akan lebih lama sebelum menjadi limbah sampah.

3. Recycle (Mendaur ulang): menggunakan sebuah barang-barang bekas untuk dijadikan suatu produk baru. Cara ini perlu membutuhkan kreativitas dan tidak semua barang bisa didaur ulang kembali. Namun, sekarag sebuah industri nonformal maupun industri rumah tangga yang melakukan aktivitas daur ulang secara serius.

4. Replace (Mengganti): mengganti kebiasaan dalam menggunakan barang yang tidak ramah lingkungan menjadi barang yang lebih ramah bagi lingkungan.

Pemanfaatan limbah plastik bernilai ekonomi tinggi dapat dilakukan dengan memilah sampah sehingga menciptakan lapangan pekerjaan untuk pencari sampah plastik dan pengepul sampah plastik, pengepres, pencacah (crusher), pembuat biji plastik dan menggunakan biji plastik untuk dijadikan produk jadi. Sementara pemanfaatan limbah plasatik secara kreatif: 
- Mendaur ulang sampah dan barang-barang yang bekas merupakan cara yang paling banyak dilakukan untuk memanfaatkan sebuah sampah anorganik. Dengan demikian, beban lingkungan dapat bisa dikurangi. Pemanfaatan limbah organik dan organik berbasis $3 \mathrm{R}$ juga diterapkan kepada kelompok anak pencinta lingkungan. Dimana dinyatakan bahwa masyarakat meningkat pengetahuan pemanfaatan limbah sambah sebanyak 30 persen setelah diberi pelatihan (Suryani et al., 2019).

- Bahkan, kerajinan dari limbah plastik bisa memiliki nilai ekonomis dengan menjadikannya sebagai komoditas yang diperjual-belikan. Serta untuk menambah penghasilan masyarakat. Kerajinan limbah plastik banyak ragamnya. Contoh kerajinan berbahan limbah sampah adalah tas, dompet, dan tikar yang dibuat dari limbah bungkus atau botol plastik bekas kemasan deterjen, pewangi pakaian, sampo, dan sebagainya. Sebuah kerajinan limbah plastik bisa dibuat berbagai kerajinan. Usaha kerajinan berbahan dasar limbah plastik dapat dikelola melalui manajemen bank sampah sehingga memiliki nilai tambah bagi kesejahteraan masyarakat (Wardany, Sari, \& Mariana, 2020; Indrianti, 2016).

- Contoh lainnya adalah styrofoam yang disulap menjadi hiasan dinding atau mainan anak kecil, juga bungkus rokok ,serta juga dibuat menjadi pot bunga dan hiasan dinding, serta masih banyak lagi kerajinan yang dapat dibuat. Bahkan limbah plastik dapat dibuat ecobrick yang memiliki nilai jual kembali (Suminto, 2017).

Dampak dari kegiatan ini adalah adanya peningkatan wawasan peduli lingkungan bagi para pelaku UMKM di kawasan wisata budaya Setu Babakan yang dapat meningkatkan kualitas lingkungan yang aman, nyaman bersih dan indah. Para peserta yang hadir adalah pelaku UKM di setu babakan muda dan pemula bagi bisnis. Berikut deskriptif peserta penyuluhan tertera dalam tabel berikut ini:

Tabel 2. Deskriptif peserta kegiatan pengabdian pada masyarakat.

\begin{tabular}{ll}
\hline \multicolumn{1}{c}{ Keterangan } & \multicolumn{1}{c}{ Nilai } \\
\hline Jenis kelamin & Pria $=$ 26 Orang \\
& Wanita =12 Orang \\
Usia & 21 Tahun \\
Rerata Tingkat pendidikan & SMA/SMK \\
Rerata Jenis bisnis & Makanan, Pakaian \& Ternak Lele \\
Rerata Omzet per bulan & 1.883 .333 \\
\hline
\end{tabular}

Sumber: data primer diolah (2020).

Sebagai pelaku bisnis UKM pemula dengan rata-rata tingkat pendidikan adalah sekolah menengah atas, konsep atas bahaya penggunaan plastik sebagai pembungkus secara rata-rata sebelum dilakukan penyuluhan berkisar pada angka 66 persen. Dan Setelah dilakukan kegiatan pengabdian masyarakat ini, pengetahun peserta secara rata-rata meningkat menjadi 88 persen. Data perbandingan tingkat pemahaman akan penggunaan plastik sebagai pembungkus dapat dilihat pada grafik berikut ini:

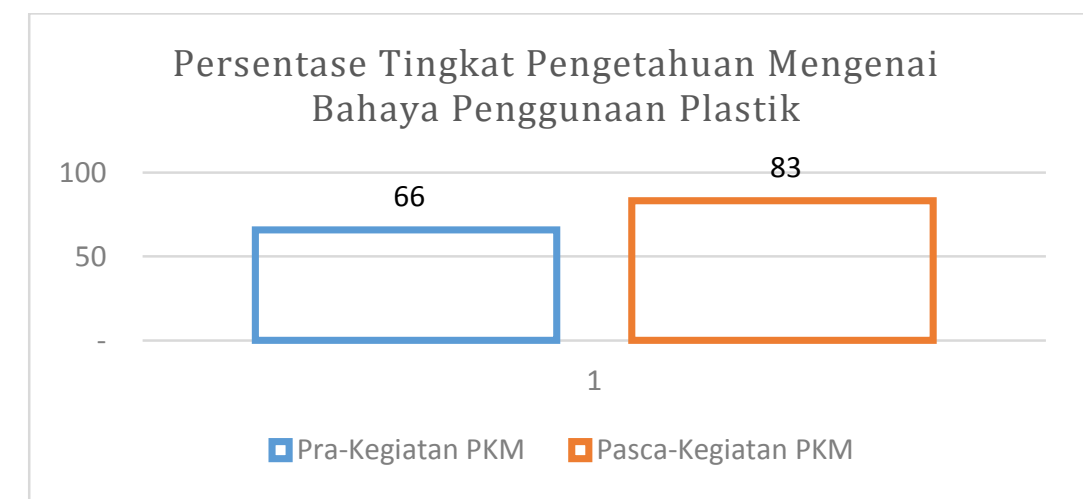

Gambar 8. Persentase tingkat pemahaman peserta penyuluhan tentang bahaya penggunaan plastik. Sumber: Data primer diolah. 
Setelah pelatihan ini didapat data bahwa 92 persen peserta akan menekan penggunaan plastik sebagai pembungkus dan 8 persen nya masih belum memiliki keinginan untuk menekan penggunaan plastik pembungkus. Berdasarkan jumlah peserta yang berkeinginan untuk menekan penggunaan plastik dapat dilihat pada grafik berikut ini:

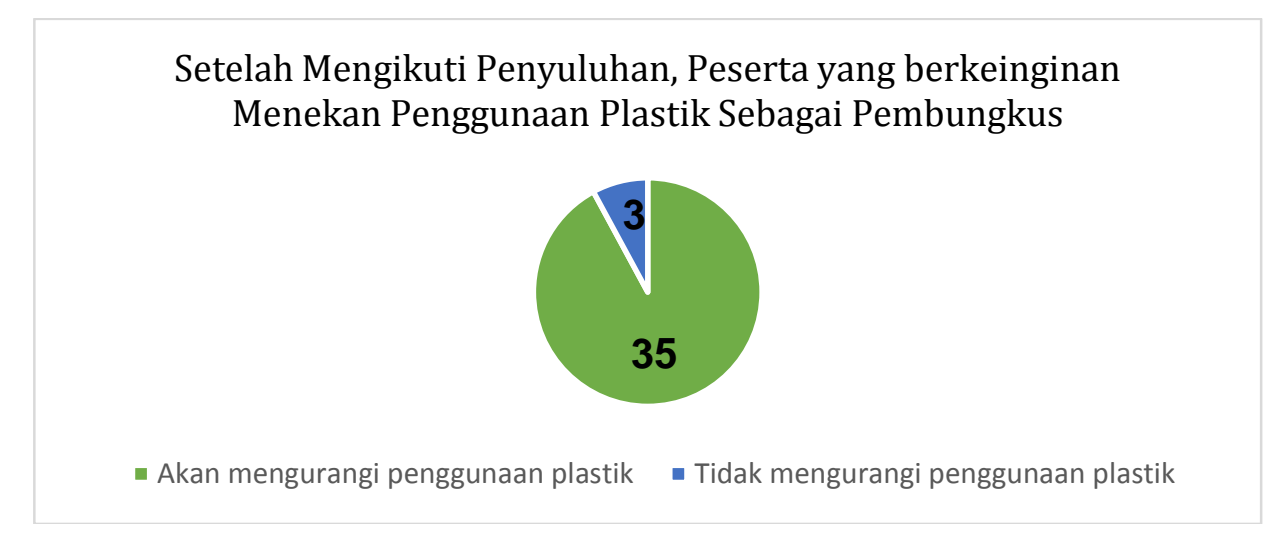

Gambar 9. Jumlah peserta penyuluhan yang berkeinginan untuk menekan penggunaan plastik setelah kegiatan pengabdian. (Sumber: Data primer diolah)

Pada kegiatan penyuluhan pengkolaborasian antara penekanan penggunaan sampah plastik dengan konsep green marketing bagi pelaku UKM di Setu Babakan didapat data bahwa melalui kegiatan ini, pemahaman mereka meningkat. Tingkat pemahaman peserta saat sebelum kegiatan pengabdian ini secara rata-rata adalah 60 persen, meningkat menjadi 75 persen setelah diberikan penyuluhan dan pemahaman.

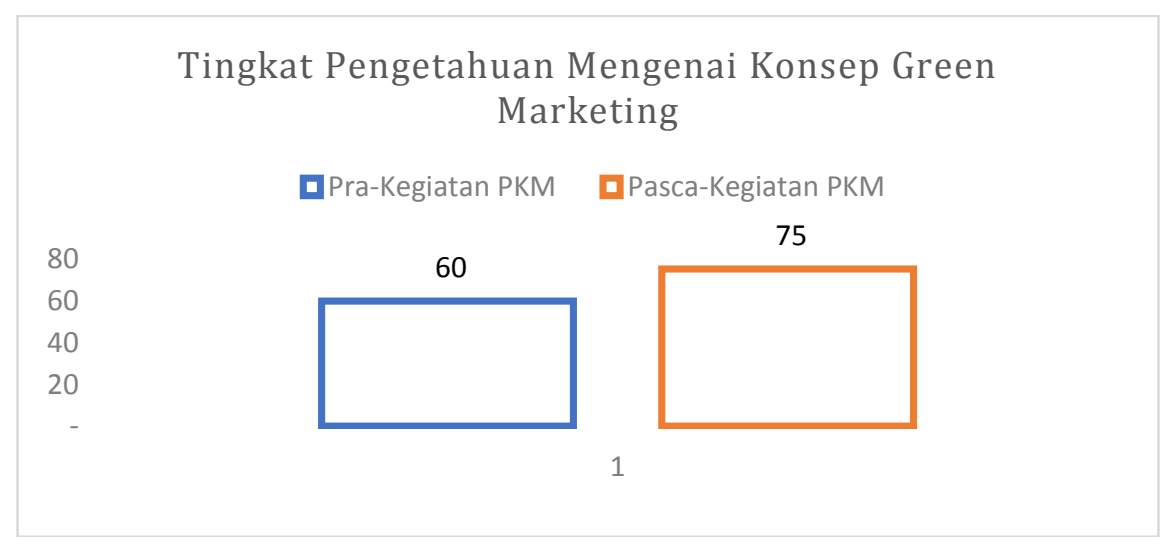

Gambar 10. Persentase tingkat pemahaman peserta penyuluhan tentang green marketing. Sumber: Data primer diolah.

Setelah dilakukan penyuluhan dan tanya jawab mengenai konsep green marketing dan bagaimana menerapkannya dalam bisnis para pelaku UKM di Setu Babakan, didapat data bahwa para 92 persen dari mereka akan berusaha untuk menerapkan konsep green marketing dan masih ada 8 persen yang tidak mau menerapkan konsep ini. Para pelaku bisnis UKM yang tidak mau menerapkan konsep ini beralasan karena para konsumen mereka masih belum bisa menghargai nilai jual produk yang ramah lingkungan. Konsumen cenderung membeli produk yang harga nya murah. Sehingga apabila mereka menerapkan harga jual yang tinggi karena menggunakan plastik ramah lingkungan, maka mereka akan rugi. Berdasarkan jumlah peserta yang berkeinginan untuk menerapkan konsep green marketing dapat dilihat pada grafik berikut ini: 


\section{Setelah Mengikuti Penyuluhan, Jumlah Peserta yang \\ Berkeinginan Untuk Menerapkan Konsep Green Marketing

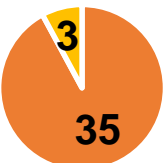 \\ - Akan menerapkan konsep green marketing \\ - Tidak menerapkan konsep green marketing}

Gambar 11. Jumlah peserta penyuluhan yang berkeinginan untuk menerapkan konsep green marketing. Sumber: Data primer diolah.

Secara umum, dari total tiga puluh delapan, 97 persen peserta yang menyatakan bahwa kegiatan pengabdian ini memberikan manfaat dan meningkatkan pemahaman mengenai pengurangan penggunaan plastik dan konsep green marketing. Berdasarkan jumlah peserta yang menyatakan bahwa kegiatan ini bermanfaat atau tidak dapat dilihat pada grafik berikut ini:

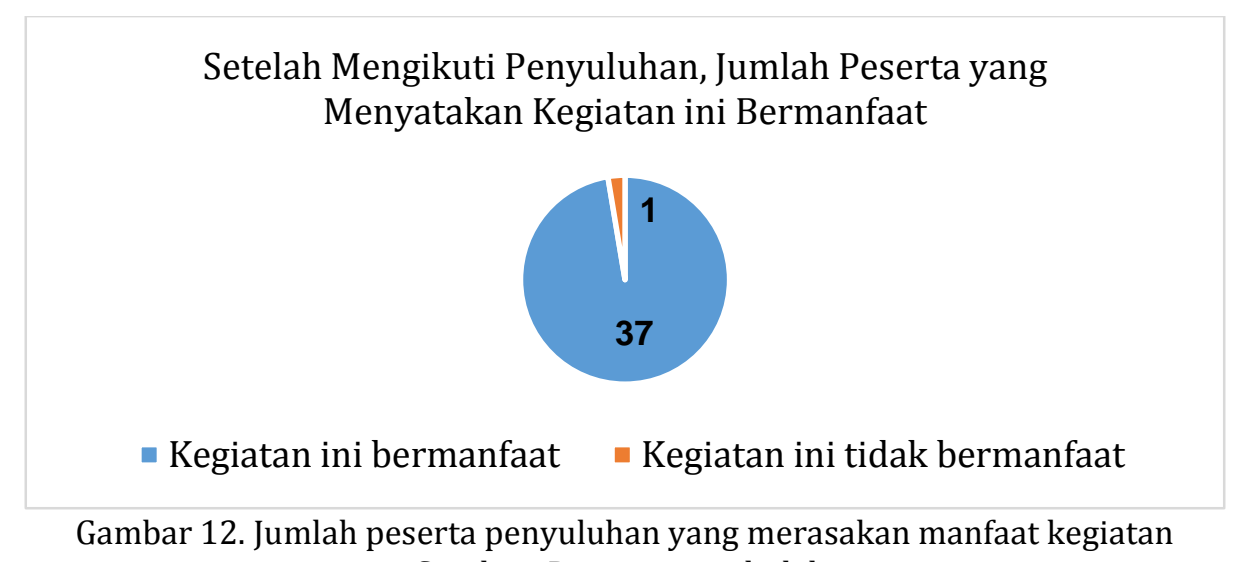

Sumber: Data primer diolah.

Berdasarkan wawancara kepada peserta yang tidak merasakan manfaat, dijelaskan bahwa alasan mereka tidak menerima manfaat karena yang dibutuhkannya adalah modal untuk berdagang dan segmen konsumen yang berada pada tingkat ekonomi rendah.

Secara keseluruhan, pelaksanaan kegiatan pengabdian kepada masyarakat ini terdorong oleh faktor-faktor :

a. Antusiasme para pelaku UKM di Cagar Budaya Betawi Setu Babakan Jakarta Selatan.

b. Adanya inergi positif antara Institut Bisnis dan Informatika (IBI) Kosgoro 1957 dengan masyarakat disekitar kampus sehingga dengan kegiatan ini diharapkan dapat meningkatkan citra positif kampus Institut Bisnis dan Informatika (IBI) Kosgoro 1957.

c. Adanya peran serta dan dukungan dari Tim Promosi Institut Bisnis dan Informatika (IBI) Kosgoro 1957.

Namun terdapat kendala sebagai faktor penghambat dalam kegiatan, yaitu terjadinya pandemi Covid-19 sehingga kegiatan berjalan terlambat dari jadual. Kondisi ini menghambat jumlah peserta yang dapat hadir karena kegiatan harus dilakukan dengan protokol pencegahan Covid-19 yang ketat. 


\section{KESIMPULAN} berikut :

Berdasarkan pelaksanaan kegiatan pengabdian ini, dapat ditarik kesimpulan sebagai

1. 92 persen peserta akan menekan penggunaan plastik sebagai pembungkus dan 8 persen nya masih belum memiliki keinginan untuk menekan penggunaan plastik pembungkus.

2. 92 persen dari mereka akan berusaha untuk menerapkan konsep green marketing dan masih ada 8 persen yang tidak mau menerapkan konsep ini.

3. 97 persen peserta yang menyatakan bahwa kegiatan pengabdian ini memberikan manfaat dan meningkatkan pemahaman mengenai pengurangan penggunaan plastik dan konsep green marketing.

\section{UCAPAN TERIMA KASIH}

Tim pelaksana mengucapkan terima kasih Institut Bisnis dan Informatika (IBI) Kosgoro 1957 yang telah memberi dukungan dana terhadap kegiatan pengabdian ini.

\section{DAFTAR PUSTAKA}

Badan Pusat Statistik. (2018). Statistik Lingkungan Hidup Indonesia (SLHI) 2018. Badan Pusat Statistik/BPS-Statistics Indonesia, 1-43. https://doi.org/3305001

Bank Indonesia. (2013). Kajian Kesiapan UMKM Ramah Lingkungan Dalam Mendapatkan Akses Pembiayaan.

Dewi, A. P., \& Yesti, Y. (2018). Pengujian Biodegradasi Filem Plastik Campuran Polimer Sintetis ( Polistiren ) Dan Biopolimer. Prosiding Seminar Nasional Fisika Universitas Riau Ke-3 2018, (29 September 2018), 76-82.

DKI Jakarta. Peraturan Daerah Provinsi Daerah Khusus Ibukota Jakarta No. 3 Th. 2013, jakarta.go.id $\S(2005)$.

Fitriah, I., Yusup, I. R., Fujiarti, I. A., Sudarmika, I., \& Ramadhanty, L. (2019). Potensi Bencana Dibalik Volume Sampah Anorganik Dalam Kegiatan Perkuliahan. Jurnal Bio Educatio, 4(4), 95105.

Hahladakis, J. N., Velis, C. A., Weber, R., Iacovidou, E., \& Purnell, P. (2018). An overview of chemical additives present in plastics: Migration, release, fate and environmental impact during their use, disposal and recycling. Journal of Hazardous Materials, 344, 179-199. https://doi.org/10.1016/j.jhazmat.2017.10.014

Haryono, A., Astrini, N., \& SR, W. (2001). Sintesa Polistirena Sulfonat Sebagai Koagulan Polimer. In Prosiding Simposium Nasional Polimer IV ISSN 1410-8720 (Vol. 2, pp. 61-66).

Hayati, N., \& Suryasih, I. A. (2019). Strategi Pengelolaan Kampung Betawi Setu Babakan Sebagai Daya Tarik Wisata Di Jakarta Selatan. Jurnal Destinasi Pariwisata, 7(1), 105. https://doi.org/10.24843/jdepar.2019.v07.i01.p16

Indrianti, N. (2016). Community-based Solid Waste Bank Model for Sustainable Education. Procedia - Social and Behavioral Sciences, 224(August 2015), 158-166. https://doi.org/10.1016/j.sbspro.2016.05.431

Karuniastuti, N. (2016). BAHAYA PLASTIK. Forum Teknologi, 03(1), 6-14.

Kementerian Keuangan RI, (2019) 'Media Keuangan Transparansi Infoemasi Informasi Kebijakan Fiskal', Media Keuangan, XIV(144), pp. 1-30.

Peraturan Pemerintah Indonesia,. (2017). Kebijakan Dan Strategi Nasional Pengelolaan Sampah Rumah Tangga Dan Sampah Sejenis Sampah Rumah Tangga, 1-15. Retrieved from https://peraturan.bpk.go.id/Home/Details/73225/perpres-no-97-tahun-2017

Pelley, J. (2018). Plastic Contamination of the Environment: Sources, Fate, Effects, and Solutions. American Chemical Society, 11.

Permata Dewi, A., \& Yesti, Y. (2018). Pemanfaatan Limbah Plastik Menjadi Kemasan Ramah Lingkungan Serta Uji Biodegradasinya. JOPS (Journal Of Pharmacy and Science), 1(2), 33-38. 
https://doi.org/10.36341/jops.v1i2.492

Purwaningrum. (2016). Upaya Mengurangi Timbulan Sampah Plastik. Jurnal Teknik Lingkungan, $8(2)$, 141-147.

Retrieved

from

https://www.trijurnal.lemlit.trisakti.ac.id/urbanenvirotech/article/view/1421

Sahwan, F. L. et al. (2005) 'Sistem Pengelolaan Limbah Plastik di Indonesia', Jurnal Sistem Pengolahan Limbah J. Tek. Ling. P3TL-BPPT, 6(1), pp. 311-318.

Septiani, B. A., Arianie, D. M., Risman, V. F. A. A., Handayani, W., \& Kawuryan, I. S. S. (2019). PENGELOLAAN SAMPAH PLASTIK DI SALATIGA: Praktik, dan tantangan. Jurnal Ilmu Lingkungan, 17(1), 90. https://doi.org/10.14710/jil.17.1.90-99

Suminto, S. (2017). Ecobrick: solusi cerdas dan kreatif untuk mengatasi sampah plastik. PRODUCTUM Jurnal Desain Produk (Pengetahuan Dan Perancangan Produk), 3(1), 26. https://doi.org/10.24821/productum.v3i1.1735

Suryani, L., Aje, A. U., Tute, K. J., Flores, U., Studi, P., Informatika, S., ... Universitas, I. (2019). Kabupaten Ende Dalam Pegelolaan Limbah Organik Dan Anorganik Berbasis 3R Untuk Mengeskalasi Nilai, 3(2), 1-8.

Wardany, K., Sari, R. P., \& Mariana, E. (2020). Sosialisasi Pendirian “ Bank Sampah ” Bag i Peningkatan, 4(2), 364-372.

www.greenpeace.org.

Yana, S., \& Badaruddin. (2017). Pengelolaan Limbah Plastik Sebagai Upaya Pengurangan Pencemaran Lingkungan Melalui Transformasi Yang Memiliki Nilai Tambah Ekonomi. Serambi Engineering, II(4), 157-164. 